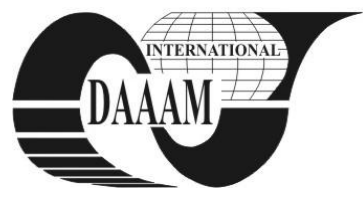

\title{
SAFETY DISTANCE FOR VEHICLES THROUGH SIMULATION
}

\author{
BARTUNEK, M[arian]; MORAVCIK, O[liver] \& SCHREIBER, P[eter]
}

\begin{abstract}
Despite the European Commission's request to decrease the number of road fatalities, each year deaths of 43000 people still occur during 1.3 million road accidents and 1.7 million people are injured. The main reason of road accidents is the driver's behaviour: excessive speed, alcohol, tiredness etc.

The development of assistance systems is directed towards isolated systems of cars, by this problematic and slower way, a definition and development of standards for road danger zones and special markings (that are directly designed for assistance systems) could then be produced and implemented.

Key words: safety, braking distance, braking force, adhesion, simulation
\end{abstract}

\section{INTRODUCTION}

Avoiding a collision on danger zones is nowadays solved by markings (electronic boards/mainly on highways or common road signs), radar installations, and road mirrors on junctions etc. On European roads there is still a lack of reliable marking directly designed for an assistance system which would be able to react on excessive speed of the driver by decreasing the car's speed after consideration of the car's surroundings (overtaking etc.). The intention of this paper is a proposal of road danger zones marking and an assistance system to eliminate serious accidents caused by excessive speed. During the following research there has to be set situations during which the speed on road danger zones can not be decreased.

\section{ROAD ACCIDENCE FACTORS AND ROAD'S DANGER ZONES}

Four factors contribute to the vast majority of collisions. In ascending order they are: equipment failure, roadway design, poor roadway maintenance, driver behaviour.

Over $95 \%$ of motor vehicle accidents (MVAs, in the USA, or Road Traffic Accidents, RTAs, in Europe) involve some degree of driver behaviour combined with one three other factors. Drivers always try to blame road conditions, equipment failure, or other drivers for those accidents.

The faster the speed of a vehicle, the greater the risk of an accident. The forces experienced by the human body in a collision increase exponentially as the speed increases. Most people agree that going $100 \mathrm{mph}$ is foolhardy and will lead to disaster. The problem is that exceeding the speed limit by only $5 \mathrm{mph}$ in the wrong place can be just as dangerous. Speeding is a deliberate and calculated behaviour where the driver knows the risk but ignores the danger. $90 \%$ of all fully licensed drivers speed at some point in their driving career; $75 \%$ admit to committing this offense regularly.

The definition of a road danger zone is meant for places on the roads where accidence occur frequently. These places are different and often it looks as if the accident can not happen (except due to technical problems). Such places can be found in the Ministry of Internal Affairs of the Slovak republic pages.
Presently there are more concepts for driving automation. Main attention is paid to highways. A car is automatically driving to the destination point set by the driver when entering the highway. When about to leave the highway the driver is alerted by the system to take control again. From a technical point of view, this concept is almost complete (Broucke \& Varaia, 1997). In this case the driving is automated by the driver's will. However the accidents happen according to the chapter mentioned above, mainly from the conscious behavior of the driver - exceeding the speed.

The marking of a road's danger zones has to fulfil the following conditions:

- It has to be deployed according to the whole lateral width of the road (the car can not miss the marking),

- It has to be easy for installation (economical aspect),

- It has to be fully reliable in regard of function,

- It has to be resistant to strong weather conditions,

- It has to be effective in regard of assistance system processing.

One of the many solutions for marking is in using permanent magnets. They are spaced on the road according to the maximum allowed speed on road danger zones we only need to define the number of magnets we want read by the assistance system per time unit. If we will define 3 magnets per one second to be read, the distance of magnets can be found in Tab. 1. The example is shown on Fig.1 By this simple marking we don't know the exact maximum speed however we know that the maximum allowed speed was exceeded (we have to count a maximum of three impulses per second).

\begin{tabular}{|c|c|c|}
\hline $\begin{array}{c}\text { Maximum } \\
\text { allowed speed } \\
\text { on road danger } \\
\text { zone }[\mathrm{km} / \mathrm{h}]\end{array}$ & $\begin{array}{c}\text { Maximum } \\
\text { allowed speed } \\
\text { on road danger } \\
\text { zone [m/s] }\end{array}$ & $\begin{array}{c}\text { Distance between } \\
\text { permanent magnets } \\
{[\mathrm{m}]}\end{array}$ \\
\hline $20 \mathrm{~km} / \mathrm{h}$ & $5,56 \mathrm{~m} / \mathrm{s}$ & 1,85 \\
\hline $40 \mathrm{~km} / \mathrm{h}$ & $11,11 \mathrm{~m} / \mathrm{s}$ & 3,70 \\
\hline $60 \mathrm{~km} / \mathrm{h}$ & $16,67 \mathrm{~m} / \mathrm{s}$ & 5,56 \\
\hline $90 \mathrm{~km} / \mathrm{h}$ & $25,00 \mathrm{~m} / \mathrm{s}$ & 8,33 \\
\hline
\end{tabular}

Tab. 1. Distance between magnets for different maximum allowed speed on road danger zones

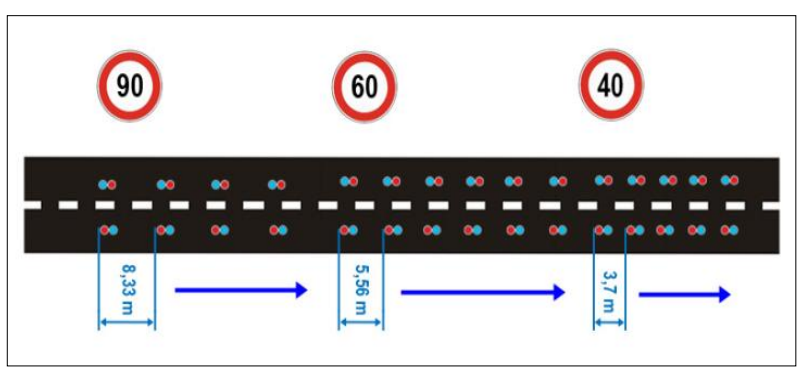

Fig. 1. Permanent magnets spaced on the road danger zones for different allowed maximum speeds 


\section{SCANNING MODUL FOR ASSISTANCE SYSTEM}

The scanning module has to collect data from sensors for the electronic control unit. The main requirement is to design such a number of sensors that the marking of the road can be detected on any area of the road (see Fig.3). Magnet marking can be scanned by Hall sensors for a magnetic field. Fig. 2 presents the marking and scanning principle on the danger zone of the road and the signal on the Hall sensor (Us) and pulse shaping circuit (Ut).

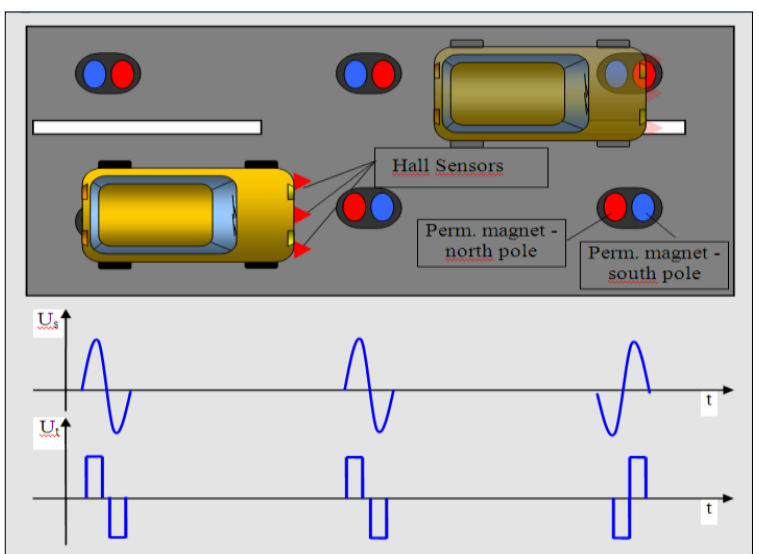

Fig. 2. Scanning of a dangerous road place by Hall sensors

\section{ASSISTANCE SYSTEM FOR DECELERATION ON ROAD DANGER ZONE TABLES} 2006):

We can divide assistance systems into two groups (Vlk,

-assistance systems for safe driving of a car

-assistance systems for driver support

If it is possible to work without the driver's intervention in a way that the control unit determines necessity for its intervention, the driver can not inhibit its function. They are mainly controlled by microprocessor and there is a necessitated speed and precision together with a decision circuit program fed by the input sensors. Examples of assistance systems for the safe driving of a car are as follows: Anti-lock braking system ABS, Electronic brake force distribution EBD, Anti-Slip Regulation ASR, Electronic stability program ESP, Active Freeze Suspension AFS. A trend of assistance systems in the future with situations when the assistance system is activated is shown in Fig. 3. A critical situation is when there is no possible way to avoid an accident. According to (Schneider, 2005), assistance system Pre-crash Braking-control intervenes in the case when the driver's avoidance action is judged inappropriate to avoid a collision and a crash is thus inevitable.

To avoid unwanted intervention of assistance by the system there has to be a considered situation of the car on the road. To get correct information about the surroundings ACC sensors (Yoshida; Kurod \& Nishigaito, 2004) can be used. Regarding ACC systems already installed into the car, the assistance system for the car's speed to decrease on the road's danger zone, can be included in this module. On the hardware level, there has to be sensors attached to read information from the road's danger zone (for example Hall sensors) and eventually a scanning module. Excessive speed on the road's danger zone is detected by first scanning the impulses after which the timer/counter is activated. When the second impulse is scanned the timer/counter calls for an interrupt and the value from it can be directly used for comparison with a defined time.

If we have defined such distances between magnets, a maximum of 3 magnets per magnets per second can be read then tcc can not be under 0,33 second.

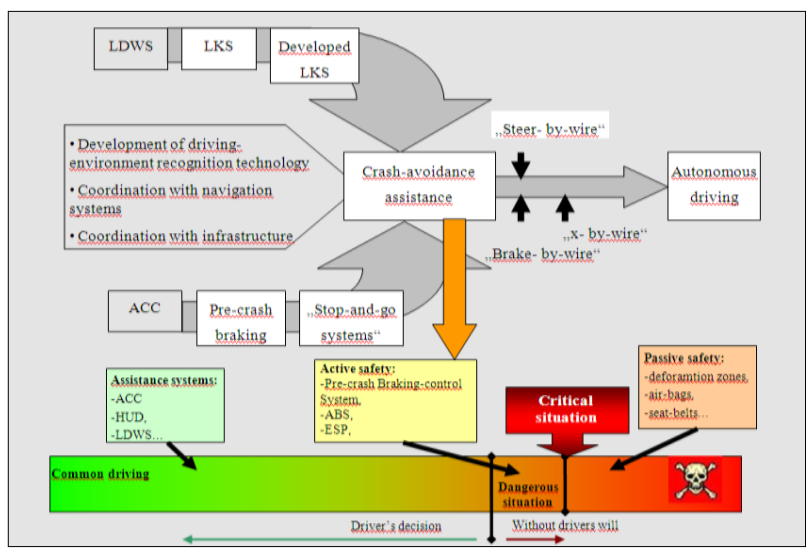

Fig. 3. Scanning of dangerous road place by Hall sensors

After detection of the maximum allowed speed increase, there has to be consideration for the car's state on the road. A car during overtaking can not be slowed down. There has to be defined states during which the speed decreases and is inhibited. The most probable combination for serious accidents is due to a driver's lack of experience when driving too fast. One alternative of how to get this data is implementation of EEPROM memory card where the kilometres could be stored.

\section{CONCLUSION}

Road danger zones are often at different places. By this we have to distinguish the situations which can happen there. A solution is to install a transmitter which can emit the signal for cars with information adjusted in regard to accidents that have already happened there.

\section{REFERENCES}

Accident Zones, Available from: http://www.minv.sk/ ?nehodove-useky-2 Accessed: 2011-7-9

Broucke, M. \& Varaia, P. (1997), The automated highway system, In: A transportation technology for the 21st century, Control engineering practice, P. 1583-1590

Highway Safety, Available from: http://ec.europa.eu/healtheu/my_environment/road_safety/index_sk.htm Accessed: 2011-7-2

Schneider, M. (2005), Automotive Radar - Status and Trends, The German Microwave Conference - GeMiC 2005, University of Ulm

Tanuška, P., Kuník, S., Kopček, M. (2009). Exothermic Cstr: Modeling, control \& simulation. In: Annals of DAAAM and Proceedings of DAAAM Symposium. - ISSN 17269679. - Vol. 20, No. 1 Annals of DAAAM 2009 \& Proceedings of the 20th international DAAAM symposium "Intelligent manufacturing \& automation, November 2009, Vienna, Austria, ISBN 978-3-901509-70-4, s. 0203-0204

Vazan, P., Moravcik, O., Krizanova, G. (2008). The comparison of selected algorithms of simulation optimization. In: Annals of DAAAM for 2008 \& proceedings of the 19th international DAAAM symposium, Book Series: Annals of DAAAM and proceedings p. 14611462

Vlk, F. (2006). Automobilová elektronika 1 Asistenční a informační systémy (Automotive Electronics 1, Assistence and Information Systems), Brno, ISBN 80-2396462-3

Yoshida, T., Kuroda, H. \& Nishigaito, T. (2004), Adaptive driver assistance system, Hitashi review, p. 212-216

What Causes Car Accidents?, Available from: http://www. smartmotorist.com/traffic-and-safety-guideline/whatcauses-car-accidents.html 2011-7-2 